\title{
Effects of land urbanization and land finance on carbon emissions: A panel data analysis for Chinese provinces
}

\begin{abstract}
The rapid urbanization in China comes with several economic, social, and environmental issues, most of which are related to land use. This study contributes to research on the land-growth-environment nexus by investigating the effect of land urbanization and land finance on carbon emissions in China from 2004 to 2013 using the Stochastic Impacts by Regression on Population, Affluence, and Technology (STIRPAT) model. Results show that land finance and land urbanization significantly affect carbon emissions. The rate of land urbanization contributes to the reduction of carbon emissions; however, it has less impact compared with other determinants. The effect of land finance and land urbanization on carbon emissions indicates that a local government's willingness to lease land for revenue aggravates carbon emissions. Economic growth and industrial structure also influence carbon emissions. Furthermore, the land requisition system and rural land conversion market should be enhanced through the guidance provided by the 13th Five-Year Plan (2016-2020) to promote the diversification of land transfer, fully consider regional differences, and establish a distinct policy focus that can contribute to emission reduction and land use.
\end{abstract}

Keywords: Land urbanization; Carbon emissions; Land finance; Urban development; Land use; STIRPAT 


\section{Introduction}

With rapid urbanization, leasing land to raise extra budgetary revenue has been a common fiscal phenomenon among local governments in many developing countries (Fang, 2013). Local governments in China hold a market monopoly at the first-level land market. They can acquire agricultural land at a low price and then sell it at a high price. The enormous amount of revenue can be further used on new land expropriation or combined with financial funds for city construction. For local governments, the process not only generates a significant increase in the extra budgetary revenue but also contributes to investment in infrastructure, attracts foreign investment, and promotes regional economic growth (Zhang, 2000). This revenue-generating approach of a local government is often referred to as "land finance" (Wu et al., 2015). Since the 1990s, land finance has become increasingly important and continues to accelerate China's urbanization and economic growth. According to Cao et al. (2008), land finance has existed for many years, indicating that local governments lead in the process of "land acquisition - urban sprawl—land revenue—urban construction—land acquisition again.” (Pan et al., 2015).

Over the years, land has served as one of the main sources of income for local governments in China (Tao et al., 2010). According to the Ministry of Finance's data, China's total land premium reached 3.37 trillion yuan in 2015 , which accounts for $40.6 \%$ of local fiscal revenue. This fiscal effect is derived from the various fees, taxes, and other revenues involved in land transfer (Ministry of Finance, 2016). Local governments compete for manufacturing investments, resulting in strong incentives to lease out most of their land. Meanwhile, such a practice leads to sharp urban expansion, as the urban built-up area increased from $23,943 \mathrm{~km}^{2}$ to $673,123 \mathrm{~km}^{2}$ from 2004 to 2013. Further, as land finance (reliance on land revenue) increased from $20 \%$ to $46 \%$ during the research period, carbon emissions in China also increased by $6.7 \%$ annually during the same period. Higher carbon emissions were notable in provinces like Shandong and Hebei, where land finance accounts for over $50 \%$ of local revenue and the average emission growth rate is over $10 \%$ annually. We are concerned with the causes of this phenomenon. Therefore, the present study investigated the possible relationship between carbon emissions and land finance (Svirejeva-Hopkins \& Schellnhuber, 2008; Bai et al., 2011; Wu\& Yang, 2012; Ou et al., 2013; Liu et al., 2016a). 
Development is interdependent with urbanization. As a country modernizes its cities expand, and people move from the countryside to the cities (Lian \& Lejano, 2014). This process is accompanied by an important change, that is, the conversion of large areas of cultivated land into urban land: a process known as land urbanization. Efficient land use not only contributes to urban development but also has positive effects on rural land conservation, especially in China, which faces an intense human-land relationship (Du et al., 2016). Zhou (2006) negatively viewed the massive magnitude of urban development and stated that the dualization system of urban and rural land as well as incomplete population urbanization leads to inefficient land use. According to Liu et al. (2012), "the quantity of land urbanization" refers to urban sprawl, while "the rate of land urbanization" refers to the speed of expansion. In the present study, we focus on urban land used to raise a local government's revenue during expansion, namely, urban construction land. Thus, following the study of Lin et al. (2015), the land urbanization rate in this study refers to the expansion speed of land construction.

Land use and cover change (LUCC) caused by land (landscape) urbanization and construction can lead to an increase in carbon dioxide $\left(\mathrm{CO}_{2}\right)$ emissions (Edmonds et al., 2003; Searchinger et al., 2008; Wise et al., 2015). Meanwhile, LUCC is considered the key factor affecting terrestrial carbon stocks, especially in urbanized areas (Tao et al., 2015). One of the New Normal(referred to as "Xin Changtai" in Chinese) proposed that natural law should be adopted, the most stringent conservation and intensive land-use system should be adhered to, and the land-use patterns should be changed to promote urban restructuring and development. For urban construction land, emphasis should be given to "strictly control increments and revitalize the stock of construction land, optimizing the land use structure and improving land use efficiency" (Liu et al., 2014). Additional requirements highlight border control on the urban growth boundary and advancing urbanization through sustainable land use. Moreover, the 13th Five Year Plan in 2015 proposed that "green, cycle and low-carbon development" is an important concept in the New-Type Urbanization Plan. The construction of an ecological civilization and low-carbon development should serve as the core content and the key point in the promotion of urbanization. Considerable attention has been paid to gain insight into the effects of land use on $\mathrm{CO}_{2}$ emissions. However, to the best of our knowledge, the effects of land finance and land urbanization have not been investigated. Further, given that China is a vast country with significant regional differences, 
patterns of urbanization development vary according to region. Therefore, studying the effects from the national and regional levels is necessary.

This study contributes to the literature by investigating the effect of land urbanization and land finance on $\mathrm{CO}_{2}$ emissions in China through national and regional analyses. As a country faced with an intense human-land relationship and high levels of environmental pressure, the Chinese government should pay attention to urban land use and its possible effects (Li et al., 2015). How does a local government's willingness to lease land for revenue relate to carbon emissions? How does land urbanization respond to the sustainable development of urban areas? Are the determinants of carbon emissions in China geographically different? What are the policy implications to effectively improve urban land use and thereby contribute to the environment? Using panel data covering 30 provinces in China from 2004 to 2013, we will employ the Stochastic Impacts by Regression on Population, Affluence and Technology (STIRPAT) model and spatial econometric models to investigate the effect of land urbanization and land finance on $\mathrm{CO}_{2}$ emissions, while considering regional differences in China.

\section{Research base: Carbon emissions, urban land use, and land finance}

Previous research on the subject is concerned with determinants of carbon emissions. Among these determinants, urbanization rate results in higher energy consumption and carbon emissions (Wang et al., 2014). Significant attention has long been paid to the relation between carbon emissions and urbanization (Wang et al., 2015, 2016). Xu and Lin (2015) adopted non-parametric additive regression models and found that urbanization and $\mathrm{CO}_{2}$ emissions in the eastern region of China follow an inverted U-shaped pattern. Shahbaz et al. (2016) adopted STIRPAT and found that economic growth is a major determinant of carbon emissions in Malaysia. Arvin et al. (2015) adopted a panel vector autoregressive model and confirmed that urbanization rate significantly contributes to higher $\mathrm{CO}_{2}$ emissions in $\mathrm{G} 20$ countries.

One of the notable features of urbanization is land-use change, which brings about significant environmental impacts. Over the years, extensive research has focused on land urbanization and its relationship with socioeconomic indicators. These indicators include LUCC (Parker et al., 2003; Mundia \& Aniya, 2005), health (Kiirya \& Mandere, 2012), arable land (Baessler \& Klotz, 2006), and fiscal decentralization (He et al., 2016). Furthermore, several studies have suggested that 
population growth and economic development drive land urbanization ( $\mathrm{Li}, 2015)$. The dynamic evaluation of land urbanization focused on the concept and its coordinated development with population urbanization and economic urbanization. Some analyses, on the other hand, presented provincial-, regional-, and city-level studies that focused on measuring the speed, quantity, and change of land-use structures (Li, 2012; Zhen et al., 2010; Zhao \& Chai, 2015; Zhu, 2015). In recent years, scholars started focusing on the environmental effects of land urbanization (Long et al., 2016). For instance, $\mathrm{Xu}$ and Zhang (2016) verified the bidirectional causal relationship between the quality of land urbanization and carbon emissions in China.

Rapid land-centered development in China has also been apparent in recent years. Revenues from selling land are essential to starting urbanization and attracting investment into the city. In the promotion of modernization and land urbanization in China, land finance effectively increases local revenue and significantly contributes to the development and modernization of urban construction: land finance (1) speeds up economic development and the construction of new urban areas, promotes and attracts capital accumulation, and even contributes to the development of modern and tertiary industries; (2) accelerates urbanization and promotes the benefits of urban agglomeration; and (3) promotes urban infrastructure, transportation facilities, and other "hard environments" (Pan et al., 2016; Zhang \& Wu, 2016).

Existing studies have focused on the institutional foundation and social influence of land finance (Heikkila, 2007; Li, 2015; Fu, 2015). Land finance usually represents a positive opportunity for local development and economic growth in China (Jia \& Liu, 2012). Moreover, Wu et al. (2015) suggested that the two primary reasons for land finance are fiscal decentralization and the competition among city governments. Chen and $\mathrm{Hu}$ (2015) found that land finance contributes negatively to the number of urban public green spaces. Moreover, land finance strategy stimulates real estate markets, which pushes housing prices up even further (Fang \& Zi, 2012; Pan et al., 2015). Wang and Ye (2015) found that land finance is significantly influenced by external fiscal circumstances, the career concerns of local leaders, and other political factors.

When land finance serves as the dominant factor for urban development, especially in China's case with both targets in the reduction of carbon emission and intense land-population relationship, further study on the effect of land urbanization, land finance, and $\mathrm{CO}_{2}$ emissions is necessary. Although the existing research has extensively covered the land-growth-environment 
nexus from various aspects, research on the environmental effects of land urbanization in China is limited; thus, the lack of policy guidance (Zhang \& Xu, 2016). To enrich the study in the related area, the present study takes into consideration regional differences, and accounting measures for regional differences are provided to understand the relationship between the variables.

\section{Material and methods}

\subsection{Data source}

Drawing upon Wang et al. (2014), we calculated $\mathrm{CO}_{2}$ emissions for 30 provinces in China from 2004 to 2013. However, the data for Tibet are unavailable for most years. Data on energy consumption were obtained from the China Energy Statistical Yearbook (2005-2014). The local fiscal budget and other economic indicators were obtained from the China Urban Construction Statistical Yearbook (2005-2014). To ensure comparability and eliminate the influence of inflation, we converted the gross domestic product (GDP) in different regions according to the constant price index in 2000.

\subsection{Carbon emission from energy consumption}

Taking into consideration data availability and previous research, this study employed carbon emissions from energy consumption (Wang et al., 2014; Fang et al., 2015; Li et al., 2016). For carbon emissions, production- and consumption-based accounting measures have been developed (Mi et al., 2016). Considering that China's statistics agency did not disclose data on $\mathrm{CO}_{2}$ emissions at the provincial and city levels, previous studies estimated $\mathrm{CO}_{2}$ emissions in China using the Intergovernmental Panel on Climate Change (IPCC) approach (Guan et al., 2012; Mi et al., 2014; Li et al., 2015; Liu et al., 2015). Considering that $95.3 \%$ of current global $\mathrm{CO}_{2}$ emissions are from fossil fuels, the negative impact of hydropower, nuclear power, and other new energy emissions is negligible (Olivier et al., 2012). The situation in China regarding carbon emissions from energy consumption is being addressed (Zhao et al., 2014) because this form of carbon emission accounts for approximately $90 \%$ of China's total carbon emissions. Therefore, energy-related $\mathrm{CO}_{2}$ emissions were calculated using the unified standard method recommended by the IPCC guidelines (IPCC, 2015; Solomon, 2007; Zhao et al., 2011). The formula is expressed as

$$
C E=\sum_{i=1}^{8} S_{i} * F_{i} * M_{i}
$$


where $C E$ is the total amount of carbon emission; $S_{i}$ is the standard coal coefficient of energy type $i ; M_{i}$ is the consumed amount of energy type $i ; F_{i}$ is the carbon emission coefficient of energy type $i$; and $i$ denotes the energy types, including coal (coal, coke), oil (crude oil, diesel, gasoline, kerosene, fuel oil), and natural gas. The average value of coal and the natural carbon emission coefficient in existing studies is adopted from the following sources: The United States Department of Energy, The United States Energy Information Administration, The Institute of Energy Economics, Japan, the National Science and Technology Commission Climate Change Programs, the Chinese Academy of Engineering, and the Greenhouse Gas Control Project from National Environmental Protection Administration. The carbon emission coefficients of other energy types are from IPCC (Chuai et al., 2012; Chen et al., 2014). The adopted average coefficient values for coal, oil, and natural gas carbon emissions are listed in Table 1 (Lou \& Li, 2011; Chuai et al., 2012).

Table 1 Carbon emission coefficients and standard coal coefficients of major energy types

\begin{tabular}{lll}
\hline \multirow{2}{*}{ Energy } & \multicolumn{2}{c}{ Carbon emission coefficient $(\mathrm{t} / \mathrm{t})$} \\
\hline Coal & 0.711 & 0.714 \\
Coke & 0.855 & 0.971 \\
Crude oil & 0.586 & 1.429 \\
Gasoline & 0.554 & 1.471 \\
Diesel & 0.592 & 1.457 \\
Kerosene & 0.571 & 1.471 \\
Fuel oil & 0.619 & 1.529 \\
Natural gas & 0.418 & 1.33 \\
\hline
\end{tabular}

\subsection{The STIRPAT Model}

The original form of the STIRPAT model is the IPAT model, which was first presented by Ehrlich and Holden (1971) to assess population (P), affluence (A), technology (T), and other social and economic driving factors of environmental pressure (I). The IPAT model is expressed as

$$
I=P A T
$$


where I represents the environmental pressure, P represents the population scale, A represents the economic factor, and T represents technology. The IPAT model provides support for the analysis in this research. However, the IPAT model has some limitations: it has a limited number of study variables and can only establish a proportional influence of the independent variable on the dependent variable. To overcome these drawbacks, Dietz and Rosa (1994) developed the IPAT model into a stochastic model, that is, the STIRPAT model. The basic STIRPAT model can be expressed as

$$
I=a P^{b} A^{c} T^{d}
$$

where a is the coefficient; b, c, and d, are exponents of the population scale (P), affluence (A) and technology (T), respectively; and e is the random error term of the model.

To overcome the heteroscedasticity of the STIRPAT model, that is, the different variances of the error term, researchers often apply a logarithm on both sides of the model. The logarithm of the STIRPAT model is flexible, thereby allowing for the inclusion of several other factors. The logarithm of the STIRPAT model serves as an effective quantitative analysis method of environmental pressure on human factors that has been extensively used in research on ecological footprint, energy footprint, and $\mathrm{CO}_{2}$ emissions (Lin et al., 2009; Wang et al., 2013; Zhao et al., 2014):

$$
\begin{aligned}
& \ln C E=\alpha+\beta_{1}(\ln L U P R)+\beta_{2}(\ln P T I)+\beta_{3}(\ln G D P)+\beta_{4}(\ln L F)+\beta_{5}(\ln P) \\
& +\varepsilon
\end{aligned}
$$

where $\mathrm{CE}$ is carbon emissions, represented by the total carbon consumption (unit: 10,000 tons); LUPR is land urbanization rate, represented by the annual growth rate of construction land (unit: \%); GDP is gross domestic product per capita, represented by the level of economic development (unit: RMB 100,000 yuan)—all GDP indexes of different years are converted according to constant price index in 2000; LF is land finance, represented by the ratio of land transfer revenue devoted to local public budgetary revenue (unit: \%); $\mathrm{P}$ is urban population scale (unit: 10,000 people); and PTI is proportion of tertiary industry, represented by the GDP ratio of tertiary industry (unit: \%).

3.4 The spatial panel-data econometric model 
This study adopted the spatial panel-data econometric model, which combines the spatial econometric method and the panel-data method. The difference between the spatial panel-data econometric model and the traditional panel-data model is the first introduction of both temporal and spatial characteristics into the research system; this approach improves the accuracy of estimation results (Elhorst, 2014; Liu et al., 2016b). Among spatial panel data models, the spatial autoregressive model (SAR), the spatial errors model (SEM), and the spatial Durbin model (SDM) are most commonly used (Han \& Lee, 2013; López, 2013). Formulas used in this paper are shown below (Elhorst, 2004):

$$
\begin{aligned}
& \ln C E_{i t}=\alpha+\rho \sum_{i=1}^{m} W_{i j} \ln C E_{i t}+\beta_{1}\left(\ln L U P R_{i t}\right)+\beta_{2}\left(\ln P T I_{i t}\right)+\beta_{3}\left(\ln G D P_{i t}\right)+\beta_{4}\left(\ln L F_{i t}\right) \\
& +\beta_{5}\left(\ln P_{i t}\right)+\varepsilon_{i t}
\end{aligned}
$$

In the above equation, $\ln C E_{i t}$ is the carbon emission of region i at time $\mathrm{t} ; \ln L U_{i t}, \ln G D P_{i t}$, $\ln L F_{i t}, \ln P_{i t}$, and $\ln P T I_{i t}$ represent the determinants of carbon emissions in a given region at time t; $\alpha$ is the constant; $\beta_{i}$ is the coefficient of determinants; $\mathrm{W}$ represents the weighting matrix; $\rho$ is a spatial autocorrelation coefficient, which reflects the value and direction of spatial correlation; and $\varepsilon$ represents the vector of residuals.

$$
\begin{aligned}
& \ln C E_{i t}=\alpha+\rho \sum_{i=1}^{m} W_{i j} \ln C E_{i t}+\beta_{1}\left(\ln L U P R_{i t}\right)+\beta_{2}\left(\ln P T I_{i t}\right)+\beta_{3}\left(\ln G D P_{i t}\right)+\beta_{4}\left(\ln L F_{i t}\right) \\
& +\beta_{5}\left(\ln P_{i t}\right)+\xi_{i t} \\
& \xi_{i t}=\lambda W_{i j} \xi_{j t}+\varepsilon_{i t}
\end{aligned}
$$

In Equation (6), $\lambda$ reflects the spatial dependence of neighboring samples on the region, and $\zeta$ is the residual that follows a normal distribution. The meaning of other variables is the same as in the above equations.

$$
\begin{aligned}
& \ln C E_{i t}=\alpha+\rho \sum_{i=1}^{m} W_{i j} \ln C E_{i t}+\beta_{1}\left(\ln L U P R_{i t}\right)+\beta_{2}\left(\ln P T I_{i t}\right)+\beta_{3}\left(\ln G D P_{i t}\right)+\beta_{4}\left(\ln L F_{i t}\right)+ \\
& \beta_{5}\left(\ln P_{i t}\right)+\theta_{1} \sum_{i=1}^{m} W_{i j} \ln L U P R_{i t}+\theta_{2} \sum_{i=1}^{m} W_{i j} \ln P T I_{i t}+\theta_{3} \sum_{i=1}^{m} W_{i j} \ln G D P_{i t} \\
& +\theta_{4} \sum_{i=1}^{m} W_{i j} \ln L F_{i t}+\theta_{5} \sum_{i=1}^{m} W_{i j} \ln P_{i t}++\varepsilon_{i t}
\end{aligned}
$$

In Equation (7), $\theta_{i}$ is the spatial autocorrelation coefficients of the explanatory variable. The meaning of other variables is the same as in the above equations. 


\section{Results}

\subsection{Spatial autocorrelation test}

Before regression analysis, authentication is required by the spatial correlation test. The spatial correlation test commonly used in statistics has: LM (lag) LMERR, Robust LM (lag), and Robust LMERR (Elhorst, 2005). The Lagrange multiplier (LM) test can help in determining whether a spatial economic model is better for the estimation (Elhorst, 2005). As shown in Table 2, (1) the LM test for spatial lag is more significant than the LM test for spatial error, and (2) Moran's I statistic is larger than the critical value and statically significant at $1 \%$. Therefore, it is more appropriate than the traditional panel-data model for analyzing the relationship between land finance, land urbanization, and carbon emissions from the spatial econometric perspective.

Hausman test results reject the null hypothesis that no fixed effects exist. Furthermore, the joint likelihood ratio (LR) test of space- and time-fixed effects rejects the null hypothesis of no space- and time-fixed effects; thus, the spatial econometric model can accurately capture the relationship between land urbanization, land finance, and carbon emissions.

Table 2 Tests for spatial dependence and fixed effects in the OLS regression

\begin{tabular}{llc}
\hline Variables & panel OLS & t-value \\
\hline Constant & $-1.332^{* * *}$ & -0.647 \\
$\ln (\mathrm{LF})$ & $0.101^{* * *}$ & 3.210 \\
$\ln (\mathrm{LUPR})$ & $-0.081^{* * *}$ & -3.310 \\
$\ln (\mathrm{GDP})$ & $0.091^{* * *}$ & 4.560 \\
$\ln \mathrm{P}$ & $0.388^{* * *}$ & 10.490 \\
$\ln (\mathrm{PTI})$ & $-0.448^{* * *}$ & -5.060 \\
\hline Test & Statistics & $\mathrm{p}$-value \\
LM spatial Lag & 60.0324 & 0.0000 \\
Robust LM spatial Lag & 2.2092 & 0.142 \\
LM spatial error & 82.7059 & 0.0000 \\
Robust LM spatial error & 23.1107 & 0.0000 \\
R-squared & 0.732 &
\end{tabular}




\begin{tabular}{llc}
\hline & \multicolumn{1}{l}{ Fixed effect } & Statistics \\
\cline { 2 - 3 } The LR ratio of the joint test & Space fixed & $216.2683^{* * *}$ \\
\cline { 2 - 3 } & Time fixed & $731.8927 * * *$ \\
\hline
\end{tabular}

Note: *,**, and $* * *$ denote significance at the $10 \%, 5 \%$, and $1 \%$ levels, respectively. DOF refers to the degree of freedom.

4.2 The effect of land urbanization and land finance on carbon emissions

Given that a spatial correlation exists among land urbanization, land finance, and carbon emissions, both the LR test and the Hausman test reject the null hypothesis. Using the spatial panel-data econometric model, the results of the panel analysis on the effect of land finance and land urbanization on carbon emissions are as follows.

Table 3 Results of spatial econometric models

\begin{tabular}{|c|c|c|c|c|}
\hline \multirow{3}{*}{ Variables } & \multirow{3}{*}{ panel OLS } & SAR with space & SEM with space & SDM with space \\
\hline & & and time fixed & and time fixed & and time fixed \\
\hline & & effect & effect & effect \\
\hline \multirow[t]{2}{*}{ Constant } & $-1.332 * *$ & & & \\
\hline & -0.647 & & & \\
\hline \multirow[t]{2}{*}{$\ln (\mathrm{LF})$} & $0.127 * * *$ & $0.0778^{*}$ & $0.00726^{*}$ & $0.0725^{*}$ \\
\hline & -0.0335 & $(0.0457)$ & $(0.0466)$ & $(0.0427)$ \\
\hline \multirow[t]{2}{*}{$\ln ($ LUPR) } & $-0.206 * * *$ & $-0.102 * * *$ & $-0.102 * * *$ & $-0.0864 * * *$ \\
\hline & -0.034 & $(0.0270)$ & $(0.0274)$ & $(0.0260)$ \\
\hline \multirow[t]{2}{*}{$\ln (\mathrm{GDP})$} & $0.144 * * *$ & $0.0278 * *$ & $0.0149 * *$ & $0.0132 * *$ \\
\hline & -0.0486 & $(0.0229)$ & $(0.0226)$ & $(0.0235)$ \\
\hline \multirow[t]{2}{*}{$\ln (\mathrm{PTI})$} & $0.476 * * *$ & $-0.700 * * *$ & $-0.687 * * *$ & $-0.619 * * *$ \\
\hline & -0.0332 & $(0.101)$ & $(0.103)$ & $(0.0985)$ \\
\hline \multirow[t]{2}{*}{$\ln (\mathrm{P})$} & $-0.369 * * *$ & $0.595 * * *$ & $0.618^{* * *}$ & $0.567 * * *$ \\
\hline & -0.0936 & $(0.0465)$ & $(0.0476)$ & $(0.0458)$ \\
\hline $\mathrm{W}^{*} \ln (\mathrm{LF})$ & & & & $0.160 * * *$ \\
\hline
\end{tabular}


Note: Standard errors are in parentheses. *,**, and *** denote significance at the $10 \%, 5 \%$, and $1 \%$ levels, respectively.

$\mathrm{R}^{2}$ demonstrates that the three spatial econometric models have a better fitting effect than the OLS(Ordinary Least Squares) model, indicating that importing the spatial correlation into the econometric model can better explain the effect of determinants on carbon emissions. Comparing the three models we find that SEM has the highest goodness of fit $(0.865)$. Meanwhile, the goodness-of-fit results show that SAR (0.819) and SEM (0.830) are superior to SDM (0.792). Further evidence proves the need to import spatial effects into the model. The spatial correlation coefficient of all three models are positive and have passed the $1 \%$ significance test, indicating that the region's carbon emissions have a significant spillover effect.

Considering the values of the log-likelihood statistic and goodness of fit, SEM provides a 
better estimate of the effect. Thus, this study adopts the estimated results of the SEM analysis as the basis for the conclusions.

The demonstration effect exists in inter-regional carbon emissions, where a $1 \%$ reduction in carbon emissions in a neighboring region will lead to $0.166 \%$ reduction in that local area. Furthermore, a $1 \%$ increase in the proportion of the tertiary industry will lead to a reduction of $0.687 \%$ in carbon emissions, indicating that optimizing the industrial structure will contribute to a reduction in carbon emissions. Meanwhile, a $1 \%$ growth in land finance index will lead to a growth of $0.0276 \%$ in carbon emissions. Moreover, a $1 \%$ growth in land urbanization index will lead to a reduction of $0.102 \%$ in carbon emissions. Compared with economic growth and industrial structure, land finance and land urbanization currently have a relatively weak influence on carbon emissions. If a mature land market mechanism forms in the future, factors related to land use can be more effective in reducing carbon emissions.

\subsection{Comparative analysis of three major regions in China}

China is a vast country with significant regional differences. Land-use level and urban development vary in different regions. Therefore, studying the determinants of carbon emissions at both the national and regional levels is necessary. To enrich the relevant literature, the current study further investigates the determinants of carbon emissions at the provincial level in China. According to the National Bureau of Statistics of China, provinces are divided into three groups in accordance with their geographic position and economic development level: Eastern (i.e., Beijing, Hebei, Jiangsu, Liaoning, Shanghai, Hainan, Fujian, Tianjin, Guangdong, Guangxi, Shandong, and Zhejiang), Central (Anhui, Shanxi, Heilongjiang, Henan, Hubei, Hunan, Jilin, Jiangxi, and Inner Mongolia), and Western China (Guizhou, Chongqing, Gansu, Ningxia, Shaanxi, Sichuan, Qinghai, Yunnan, and Xinjiang). SEM is chosen for further analysis because previous estimates show that the spatial error model has better results than the other two models.

Table 4 Results of SEM in eastern, central, and western regions of China

Variables Castern China Central China Western China

$\ln (\mathrm{LF})$

0.106

$0.148^{* * *}$

0.0310

(0.0693)

$(0.0526)$ 


\begin{tabular}{|c|c|c|c|}
\hline \multirow[t]{2}{*}{$\ln (\mathrm{GDP})$} & $0.237 * * *$ & $0.410 * * *$ & $0.461 * * *$ \\
\hline & $(0.0635)$ & $(0.0760)$ & $(0.0667)$ \\
\hline \multirow[t]{2}{*}{$\ln (\mathrm{PTI})$} & $-1.646^{* * *}$ & $-0.529 * * *$ & -0.104 \\
\hline & $(0.269)$ & $(0.182)$ & $(0.128)$ \\
\hline \multirow[t]{2}{*}{$\ln \mathrm{P}$} & $0.592 * * *$ & $-0.145^{* *}$ & $0.128 * * *$ \\
\hline & $(0.0768)$ & $(0.0591)$ & $(0.0485)$ \\
\hline \multirow[t]{2}{*}{$\ln (\mathrm{LUPR})$} & $-0.141^{* *}$ & $-0.113 * * *$ & 0.0229 \\
\hline & $(0.0566)$ & $(0.0379)$ & $(0.0497)$ \\
\hline \multirow[t]{2}{*}{$\Lambda$} & 0.0732 & $-0.168 * *$ & $-0.0879^{*}$ \\
\hline & $(0.0584)$ & $(0.0756)$ & $(0.0632)$ \\
\hline \multirow[t]{2}{*}{ sigma2_e } & $0.0214^{* * * *}$ & $0.00351^{* * *}$ & $0.0203 * * *$ \\
\hline & $(0.00297)$ & $(0.000485)$ & $(0.00231)$ \\
\hline log-likelihood & 124.6742 & 156.7294 & 132.8523 \\
\hline $\mathrm{R}^{2}$ & 0.704 & 0.798 & 0.925 \\
\hline
\end{tabular}

Note: Standard errors are in parentheses. $*, * *$, and $* * *$ denote significance at the $10 \%, 5 \%$, and $1 \%$ levels, respectively.

Estimation results based on the maximum likelihood (ML) principle are presented in Table 4. The $\mathrm{R}^{2}$ of three regions are 0.704, 0.798, and 0.925, which reflect the ideal fitness of SEM.

For the eastern region, leading determinants of carbon emissions is the proportion of tertiary industry in which a $1 \%$ growth in the proportion of secondary industry will lead to a reduction of $1.646 \%$ in carbon emissions. Other determinants include land urbanization rate, GDP, proportion of secondary industry, proportion of tertiary industry, and urban population scale. For the central region, the factors that influence carbon emissions are land finance and the proportion of tertiary industry. For the western region, the factors that influence carbon emissions are land urbanization rate, proportion of secondary industry, and population scale.

Land finance is only statistically significant in Central China, where a $1 \%$ growth in land finance will lead to a growth of $0.148 \%$ in carbon emissions. The possible reason is that urban development in the central region is in a rapid economic growth phase. In its development, the central region undertakes various kinds of industrial transfer from the eastern part, which requires 
a considerable number of land factor inputs to provide basic support to urban economic growth. Furthermore, land marketization in central cities is relatively low, and land circulation is primarily under the influence of local governments. In the eastern region, where economic growth has been at a high level, the scarcity and immobility of land have led to its replacement by other elements. Moreover, the relatively backward economic development in western China made urban economic growth more dependent on national policy. The low utilization efficiency of urban construction land resulted in a relatively low contribution of land finance.

Land urbanization rate is the only factor that contributes to the reduction of carbon emissions. However, at present, it has less impact when compared with other determinants. Among the three regions in China, land urbanization rate is statistically significant at the $5 \%$ and $1 \%$ levels in Eastern and Central China, respectively. A $1 \%$ growth in land urbanization will lead to a reduction of $0.141 \%$ in carbon emissions in Eastern China and $0.113 \%$ in Central China. These findings suggest that the development quality of land urbanization in Eastern China is significant. Under the guidance of the New-Type Urbanization Plan (2014-2020), the industrial structure and other measures can be adjusted.

\section{Conclusion and discussion}

Land finance has contributed to rapid economic growth in China, especially in regional development. However, it has also brought about negative effects on social development and the environment (Zheng et al., 2014). This study started from the perspective of green development to investigate the effects of fast development on land urbanization and land finance. The issue in China has attracted increasing attention from academic circles and policy makers. By controlling for economic development, industrial structure, and population scale, our work adopts a spatial econometric model to measure the influence of land urbanization and land finance on carbon emissions in 30 provinces using annual data from 2003 to 2014 . The results are summarized as follows: (1) On a nationwide scale, land finance and land urbanization significantly affect carbon emissions. A $1 \%$ growth in land finance will lead to an increase of $0.127 \%$ in carbon emissions; a $1 \%$ growth in land urbanization will lead to a reduction of $0.206 \%$ in carbon emissions. (2) Land urbanization rate is the only factor that contributes to the reduction of carbon emissions. However, at present, it has less impact compared with other determinants. (3) Land finance is only 
statistically significant in Central China. A $1 \%$ growth in land finance will lead to a growth of $0.148 \%$ in carbon emissions. (4) Economic growth and industrial structure still serve as the main determinants on carbon emission. Thus, in the promotion of new urbanization, China needs to improve the quality of land use. The conclusions provide some relevant policy recommendations, as follows:

First, given that land finance contributes to carbon emissions on a nationwide scale, the government should promote the diversification of land transfer (Zhang et al., 2015). We have to concede that, to a certain extent, the current land conversion mechanism of Rural Collective Commercial Construction Land will ease the shortage of land supply and the issue of land finance. Nonetheless, land reform policies that involve the interests of various aspects of the process might encounter unexpected problems. Achieving the conversion from resource to capital not only contributes to the benefits of farmers but also serves urban development. Various kinds of new strategies, such as "land bank," "land shareholding," or "company plus farmers," have been used in the past. Land capitalization needs nationwide promotion and should take regional differences into consideration. Land finance might take a sizeable portion of local revenue after rapid development. Based on the existing rural household contract responsibility system, new cooperative economic organizations and land securitization contribute to the scale management of land. Moreover, emphasis should be given to the farmer's willingness in relation to the process. The latest round of land reform shows that the traditional land-use mode can be upgraded through land transfer. On the one hand, land transfer is more efficient; on the other hand, farmers' access to a stable income relies on the land.

Second, in the context of fast urbanization, existing reduction strategies can only begin with controlling the increment of carbon emissions (Jiang et al., 2016). The characteristics of the rapid urbanization growth in China need to be fully considered through the establishment of low-carbon urbanization policy standards, and strategies should emphasize China's land-use conditions to achieve the sustainable development of urbanization and a low-carbon economy. Regional differences should be given full consideration by local governments in formulating urban land policy. That is, land-use policy must be founded on the principles of regional differences to "suit the remedy to the case." For the eastern region, where the leading determinant is population scale, a reasonable control of population size and the enhancement of land-use efficiency can contribute 
to the reduction in carbon emissions. For Central China, where the coefficient of the third industry is negative, policy concerns should focus on the transformation of the industrial structure. Moreover, land finance in the central region requires special attention as it is only statistically significant in this area. For Western China, the second industrial development is the main determinant of carbon emissions. Policy focus should consider the comparative advantages to gain more human capital and investment, and to increase investment in science and technology to prevent the tension between land supply and the reduction of carbon emissions. Furthermore, deepening the resource allocation effect of market mechanisms can promote the urban and rural land market.

Third, unlike previous studies, which revealed that urbanization and land use lead to carbon emissions (Dhakal, 2009; Zhang \& Lin, 2012), our results show that land urbanization can contribute to the reduction of carbon emissions. Therefore, the ongoing industrial restructuring and green development have taken effect. Urban land use is not simply an economic issue; it is also related to ecological civilization, environmental impact, social development, and other aspects. Although a traditional, one-sided emphasis strategy has been unable to resolve new conflicts, intensive land use calls for a new guiding theory and new practice. According to Liu et al. (2014), the ultimate goal of China's land-use policy is to use land in a sustainable manner. Therefore, ecological-civilization construction and low-carbon development should serve as the core content and the key point to promote future development. Considering our results, the ongoing land urbanization can positively affect climate change. Therefore, policy formulation should also consider deepening positive outcomes. Given that land use serves as the carrier of urbanization, the quality of land urbanization should closely relate to the sustainable development of cities. In the formulation and implementation of development planning, sustainable development should be the theme for institutional innovation and local economic growth. Development planning should also highlight achievements in green development, strengthen a green assessment, weaken GDP evaluation, and increase the proportion of sustainable performance and related indicators for the evaluation of local governments.

Finally, we suggest that further progress in the quality of land urbanization and reasonable regulation on land finance would contribute to meeting the targets for the reduction of carbon emissions (Zhang \& Xu, 2016). Although it is not the leading cause, land finance can add to the 
emission of carbon dioxide, a major greenhouse gas, resulting in increased atmospheric thermal insulation capacity, global warming, and climate change. According to the Paris agreement, the average global temperature should be controlled to $2{ }^{\circ} \mathrm{C}$ above the pre-industrial level, and efforts are being made to keep the temperature within $1.5{ }^{\circ} \mathrm{C}$. Faced with pressure from the international community, China has long been making efforts to control climate change. In May 2009, the government announced a 40-45\% reduction in carbon emissions per unit of GDP in 2020 compared with that in 2005 (Yi et al., 2016).The priorities of the 13th Five-Year Plan in 2016 further raised the targets for high energy and climate requirements: the average annual energy consumption per unit of GDP dropped by $15 \%$, and the average annual $\mathrm{CO}_{2}$ emissions per unit of GDP dropped by $18 \%$. The 13th Five-Year Plan is a typical green development plan, which addresses climate change as China's national green development strategy of the important content. Nevertheless, the reduction of China's carbon emissions is a part of the government's efforts; the market system has not been fully established, which might lead to a negative outlook in terms of emission targets. Our findings call for an advanced land-use policy system to improve land-use efficiency and maintain sustainable urban development.

The most significant contribution is the attempt to identify a possible environmental effect of land finance, because no previous research has directly addressed the issue. Meanwhile, the effects of current land urbanization on carbon emissions are encouraging, as reflected in our results. In view of its vital role in urbanization, empirical studies on this topic can also be conducted in other developing countries. This research aims to contribute to the literature on land use and carbon emission as well as national policy making. In future research, aspects that have not been fully uncovered should be considered. In particular, we would like to develop studies on carbon emission and urban land use in future research. Meanwhile, other socioeconomic factors, such as the market system and household energy consumption, might affect the relationship within land finance, land urbanization, and carbon emissions. Our study can be further expanded to discuss the relationship at the city or county level, where the influence of local governments can be greater than at the provincial level. In the future, policy and institutional innovation concerning land finance and the efficiency of urban land use should be a priority in the Chinese government's agenda. 


\section{Acknowledgments}

The authors gratefully acknowledge the financial support from the National Science Foundation of China (Grants: 71203157 and 71203156). 


\section{References}

Arvin, M. B., Pradhan, R. P., \& Norman, N. R. (2015). Transportation intensity, urbanization, economic growth, and $\mathrm{CO}_{2}$ emissions in the G-20 countries. Utilities Policy, 35, 50-66.

Baessler, C., \& Klotz, S., (2006). Effects of changes in agricultural land-use on landscape structure and arable weed vegetation over the last 50 years. Agriculture, ecosystems \& environment, 115(1), 43-50.

Bai, X., Chen, J., \& Shi, P. (2011). Landscape urbanization and economic growth in China: Positive feedbacks and sustainability dilemmas. Environmental Science \& Technology, 46(1), 132-139.

Cao, G., Feng, C., \& Tao, R. (2008). Local "land finance” in China's urban expansion: challenges and solutions. China \& World Economy, 16(2), 19-30

Chen, M., Liu, W., \& Lu, D. (2016). Challenges and the way forward in China's new-type urbanization. Land Use Policy, 55, 334-339.

Chen, W., \& Hu, F. (2015). Producing nature for public: land-based urbanization and provision of public green spaces in china. Applied Geography, 58, 32-40.

Chen, Y., Chang, K., Han, F., Karacsonyi, D., \& Qian, Q. (2016). Investigating urbanization and its spatial determinants in the central districts of Guangzhou, China. Habitat International, 51, $59-69$.

Cheng, Y., Wang, Z., Ye, X., \& Wei, Y. D. (2014). Spatiotemporal dynamics of carbon intensity from energy consumption in china. Journal of Geographical Sciences, 24(4), 631-650.

Chuai, X., Huang, X., Wang, W., Wen, J., (2012). Spatial econometric analysis of carbon emissions from energy consumption in China. Journal of Geographical Sciences 22(4), 630-642.

Chuai, X., Huang, X., Wang, W., Zhao, R., Zhang, M., \& Wu, C. (2014). Land use, total carbon emissions change and low carbon land management in coastal jiangsu, china. Journal of Cleaner Production, 103, 77-86.

Dhakal, S. (2009). Urban energy use and carbon emissions from cities in China and policy implications. Energy Policy, 37(11), 4208-4219.

Dietz T, Rosa E.A. (1994). Rethinking the environmental impacts of population, affluence and technology.Human Ecology Review. 1, 277-300.

Du, J., Thill, J. C., \&Peiser, R. B. (2015). Land pricing and its impact on land use efficiency in 
post-land-reform china: a case study of beijing. Cities, 50, 68-74.

Du, J., Thill, J. C., \&Peiser, R. B. (2016). Land pricing and its impact on land use efficiency in post-land-reform China: A case study of Beijing. Cities, 50, 68-74.

Edmonds, J.A., Clarke, J., Dooley, J., Kim, S.H., Izaurralde, R., Rosenberg, N., Stokes, G., (2003).The potential role of biotechnology in addressing the long-term problem of climate change in the context of global energy and ecosystems. In: Gale, J., Kaya, Y. (Eds.), Greenhouse Gas Control Technologies. Pergamon, Amsterdam, pp. 1427-1432.

Ehrlich, P. R., \&Holdren, J. P. (1971). Impact of population growth. Science, 171(3977), 1212-7.

Elhorst, J. P. (2014). Spatial panel data models. In Spatial Econometrics (pp. 37-93). Springer Berlin Heidelberg.

Fang, L., \&Zi, S. (2012). Theory study and empirical research about impact of land finance on housing price. Resource Development and Market, 29(2), 136-140. (in Chinese)

Fang.Z. (2013). Determinants of land finance in china: a study based on provincial-level panel data. Australian Journal of Public Administration, 72(3), 293-303.

Feng, C., Xiao, Z., Shen, H., \& Zhang, L. (2016). New Urbanization and Land Use in China. In Urbanization and Locality (pp. 55-73). Springer Berlin Heidelberg.

Fu, Q. (2015). When fiscal recentralisation meets urban reforms: prefectural land finance and its association with access to housing in urban china. Urban Studies, 52(10), págs. 1791-1809.

Guan, D., Liu, Z., Geng, Y., Lindner, S., \&Hubacek, K. (2012). The gigatonne gap in china/'s carbon dioxide inventories. Nature Climate Change, 2(9).

Han, X., \& Lee, L. F. (2013). Bayesian estimation and model selection for spatial durbin error model with finite distributed lags ir. Regional Science \& Urban Economics, 43(5), $816-837$.

He, C., Zhou, Y., \& Huang, Z. (2016). Fiscal decentralization, political centralization, and land urbanization in China. Urban Geography, 37(3), 436-457.

Heikkila, E. J. (2007). Three questions regarding urbanization in china. Journal of Planning Education \& Research, 27(1), 65-81.

Intergovernmental Panel on Climate Change. (2015). Climate change 2014: mitigation of climate change (Vol. 3). Cambridge University Press.

Jia, K., \& Liu, W. (2012). Land Finance: Analysis and Resolutions. Public Finance Research, 1, 


\section{2-9.(In Chinese)}

Jiang, J., Ye, B., Ma, X., \& Miao, L. (2016). Controlling GHG emissions from the transportation sector through an ETS: Institutional arrangements in Shenzhen, China. Climate Policy, 16(3), 353-371.

Kiirya, D., \&Mandere, N., (2012).Land use change impacts on health.Land use change impacts on health. LAP LAMBERT Academic Publishing.

Li, B., Liu, X., \& Li, Z. (2015). Using the STIRPAT model to explore the factors driving regional co 2, emissions: a case of Tianjin, china. Natural Hazards, 76(3), 1667-1685.

Li, L., Hong, X., Tang, D., \& Na, M. (2016). GHG emissions, economic growth and urbanization: a spatial approach. Sustainability, 8(5).

Li, T. (2015). Land use dynamics driven by rural industrialization and land finance in the peri-urban areas of china: "the examples of jiangyin and shunde". Land Use Policy, 45, 117-127.

Li, T. J. J., Sen, S., \& Hecht, B. (2014). Leveraging advances in natural language processing to better understand Tobler's first law of geography. In Proceedings of the 22nd ACM SIGSPATIAL International Conference on Advances in Geographic Information Systems (pp. 513-516). ACM.

Li, Y., (2012). Urban-rural interaction patterns and dynamic land use: implications for urban-rural integration in china. Regional Environmental Change, 12(4), 803-812.

Li, Y., Li, Y., Westlund, H., \& Liu, Y. (2015). Urban-rural transformation in relation to cultivated land conversion in China: Implications for optimizing land use and balanced regional development. Land use policy, 47, 218-224.

Lian, H., \&Lejano, R. P. (2014). Interpreting Institutional Fit: Urbanization, Development, and China's “Land-Lost”. World Development, 61, 1-10.

Lin, S., Zhao, D., \&Marinova, D. (2009). Analysis of the environmental impact of china based on stirpat model. Environmental Impact Assessment Review, 29(6), 341-347.

Lin, X., Wang, Y., Wang, S., \& Wang, D. (2015).Spatial differences and driving forces of land urbanization in China. Journal of Geographical Sciences, 25(5), 545-558.

Liu, L. C., Wu, G., Wang, J. N., \& Wei, Y. M., (2011). China's carbon emissions from urban and rural households during 1992-2007. Journal of Cleaner Production, 19(15), 1754-1762.

Liu, Y., Xiao, H., Lv, Y., \& Zhang, N. (2015). The effect of new-type urbanization on energy 
consumptionin China: A spatial econometric analysis. Journal of Cleaner Production. doi:10.1016/j.jclepro.2015.10.044.

Liu, Y., Zhu, L., \&Yuheng, L. I. (2012). The essential theories and models of rural land consolidation in the transitional period of china. Progress in Geography, 31(6), 777-782.

Liu, Y., Fang, F., \& Li, Y. (2014). Key issues of land use in china and implications for policy making. Land Use Policy, 40(1), 6-12.

Liu, Y., Yan, B., \& Zhou, Y. (2016a). Urbanization, economic growth, and carbon dioxide emissions in China: A panel cointegration and causality analysis. Journal of Geographical Sciences, 26(2), $131-152$.

Liu, Y., Long, H., Chen, Y., Wang, J., Li, Y., Li, Y., ... \& Zhou, Y. (2016b). Progress of research on urban-rural transformation and rural development in China in the past decade and future prospects. Journal of Geographical Sciences, 26(8), 1117-1132.

Liu, Z., Guan, D., Wei, W., Davis, S. J., Ciais, P., \& Bai, J., et al. (2015). Reduced carbon emission estimates from fossil fuel combustion and cement production in china. Nature, 524(7565), $335-8$

Long, X., Ji, X., \&Ulgiati, S. (2016). Is urbanization eco-friendly? An energy and land use cross-country analysis. Energy Policy.

Lou W.,\&Li, M.(2011). Low-carbon Economy Planning: Theory,Method,and Model. Social Sciences Academic Press (China). (In Chinese)

Mi, Z. F., Pan, S. Y., Yu, H., \& Wei, Y. M. (2014). Potential impacts of industrial structure on energy consumption and co 2, emission: a case study of beijing. Journal of Cleaner Production, 103, $455-462$.

Mi, Z., Zhang, Y., Guan, D., Shan, Y., Liu, Z., \& Cong, R., et al. (2016). Consumption-based emission accounting for chinese cities. Applied Energy.

Ministry of Finance. (2016) Available from: http://zhs.mof.gov.cn/zhengwuxinxi/zonghexinxi/ 201604/t20160401_1934261.html.Ministry of Finance of the People's Republic of Chin a. (In Chinese)

Mundia, C. N., Aniya, M., 2005. Analysis of land use/cover changes and urban expansion of nairobi city using remote sensing and gis. International Journal of Remote Sensing, 26(13), 2831-2849 
Olivier, J. G. J., Janssens-Maenhout, G., \& Peters, J. A. H. W. (2012). Trends in global co2 emissions. Emissions Database for Global Atmospheric Research Edgar.

Ou, J., Liu, X., Li, X., \& Chen, Y. (2013). Quantifying the relationship between urban forms and carbon emissions using panel data analysis. Landscape ecology, 28(10), 1889-1907.

Pan, F., Zhang, F., Zhu, S., \&Wójcik, D. (2016). Developing by borrowing? Inter-jurisdictional competition, land finance and local debt accumulation in China. Urban Studies, 0042098015624838 .

Pan, J. N., Huang, J. T., \& Chiang, T. F. (2015). Empirical study of the local government deficit, land finance and real estate markets in china. China Economic Review, 32(C), 57-67.

Parker, D. C., Manson, S. M., Janssen, M. A., Hoffmann, M. J., \& Deadman, P., (2003). Multi-agent systems for the simulation of land-use and land-cover change: a review. Annals of the Association of American Geographers ,93, .314--337.

Sadorsky, P. (2014). The effect of urbanization on $\mathrm{CO}_{2}$ emissions in emerging economies. Energy Economics, 41, 147-153.

Searchinger, T., Heimlich, R., Houghton, R. A., Dong, F., Elobeid, A., Fabiosa, J.,\& Yu, T. H., (2008). Use of US croplands for biofuels increases greenhouse gases through emissions from land-use change. Science, 319(5867), 1238-1240.

Shahbaz, M., Loganathan, N., Muzaffar, A. T., Ahmed, K., \&Jabran, M. A. (2016). How urbanization affects $\mathrm{CO}_{2}$ emissions in Malaysia? The application of STIRPAT model. Renewable and Sustainable Energy Reviews, 57, 83-93.

Solomon, S. (2007). Carbon dioxide storage: Geological security and environmental issues-Case study on the sleipner gas field in Norway. Bellona report, 128.

Svirejeva-Hopkins, A., \&Schellnhuber, H. J. (2008). Urban expansion and its contribution to the regional carbon emissions: Using the model based on the population density distribution. Ecological Modelling, 216(2), 208-216.

Tao, R., Su, F., Liu, M., \& Cao, G. (2010). Land leasing and local public finance in china's regional development: evidence from prefecture-level cities. Urban Studies, 47(10), $2217-2236$

Tao, Y., Li, F., Wang, R., \& Zhao, D., (2015). Effects of land use and cover change on terrestrial carbon stocks in urbanized areas: a study from changzhou, china. Journal of Cleaner 
Production, 103, 651-657.

Wang, P., Wu, W., Zhu, B., \& Wei, Y. (2013). Examining the impact factors of energy-related $\mathrm{CO}_{2} \mathrm{emissions}$ using the stirpat model in guangdong province, china. Applied Energy, 106(11), $65-71$.

Wang, S., Fang, C., Guan, X., Pang, B., \& Ma, H. (2014). Urbanisation, energy consumption, and carbon dioxide emissions in china: a panel data analysis of china's provinces. Applied Energy, 136(C), 738-749.

Wang, S., Fang, C., Ma, H., Wang, Y., \& Qin, J. (2014). Spatial differences and multi-mechanism of carbon footprint based on GWR model in provincial China. Journal of Geographical Sciences, 24(4), 612-630.

Wang, W., \& Ye, F. (2015). The political economy of land finance in china. Public Budgeting \& Finance.

Wang, Y., Chen, L., \& Kubota, J. (2016). The relationship between urbanization, energy use and carbon emissions: evidence from a panel of association of southeast asian nations (asean) countries. Journal of Cleaner Production, 112, 1368-1374.

Wang, Y., Zhang, X., Kubota, J., Zhu, X., \& Lu, G. (2015). A semi-parametric panel data analysis on the urbanization-carbon emissions nexus for oecd countries. Renewable \& Sustainable Energy Reviews, 48, 704-709.

Wise, M., Hodson, E. L., Mignone, B. K., Clarke, L., Waldhoff, S., \&Luckow, P., (2015). An approach to computing marginal land use change carbon intensities for bioenergy in policy applications. Economic Modelling, 47, 307-318.

Wu, C., Li, G., Yue, W., Lu, R., Lu, Z., \& You, H. (2014). Effects of endogenous factors on regional land-use carbon emissions based on the grossman decomposition model: a case study of zhejiang province, china. Environmental Management, 55(2), 1-12.

Wu, Q., Li, Y., \& Yan, S. (2015). The incentives of china's urban land finance. Land Use Policy, 42, $432-442$.

Wu, Y., \& Yang, Z. (2012). Land Finance and Optimal City Size. Research on Economics and Management, 3, 006.

Xu, B., \& Lin, B. (2015). How industrialization and urbanization process impacts on CO 2 emissions in China: Evidence from nonparametric additive regression models. Energy 
Economics, 48, 188-202.

Xu, H., \& Zhang, W. (2016). The causal relationship between carbon emissions and land urbanization quality: A panel data analysis for Chinese provinces. Journal of Cleaner Production, 137, 241-248.

Yi, B. W., Xu, J. H., \& Fan, Y. (2016). Determining factors and diverse scenarios of co 2, emissions intensity reduction to achieve the $40-45 \%$ target by 2020 in china - a historical and prospective analysis for the period 2005-2020. Journal of Cleaner Production, 122, 87-101.

Zhang, C., \& Lin, Y. (2012). Panel estimation for urbanization, energy consumption and co 2 emissions: a regional analysis in china. Energy Policy, 49(10), 488-498.

Zhang, F., \& Wu, Z. (2016). The Solution of the Dependence on Land Finance with the New-type Local Taxation System. International Journal for Innovation Education and Research, 4(7).

Zhang, R., Du, Q., Geng, J., Liu, B., \& Huang, Y. (2015). An improved spatial error model for the mass appraisal of commercial real estate based on spatial analysis: Shenzhen as a case study. Habitat International, 46, 196-205.

Zhang, T. (2000). Land market forces and government's role in sprawl: The case of China. Cities, 17(2), 123-135.

Zhang, W. \& Xu, H. Environ Dev Sustain (2016). doi:10.1007/s10668-016-9813-8

Zhao, C., Chen, B., Hayat, T., Alsaedi, A., \& Ahmad, B. (2014). Driving force analysis of water footprint change based on extended stirpat model: evidence from the chinese agricultural sector. Ecological Indicators, 47, 43-49.

Zhao, J., Chai, L., (2015).A novel approach for urbanization level evaluation based on information entropy principle: a case of beijing. Physica A Statistical Mechanics \& Its Applications, $114-125$.

Zhao, R., Chuai, X., Huang, X., Lai, L., \& Peng, J. (2014). Carbon Emission and Carbon Footprint of Different Industrial Spaces in Different Regions of China. Assessment of Carbon Footprint in Different Industrial Sectors, Volume 1. Springer Singapore,191-200.

Zhao, R., Huang, X., Zhong, T., \& Peng, J. (2011). Carbon footprint of different industrial spaces based on energy consumption in china. Journal of Geographical Sciences, 21(2), 285-300.

Zhen, L., Wei, Y., Xie, G., Helming, K., Cao, S., Yang, L., ... \&König, H. (2010). Regional analysis of dynamic land use functions in China. ShengtaiXuebao/ActaEcologicaSinica, 
30(24), 6749-6761.

Zheng, H., Wang, X., \& Cao, S. (2014). The land finance model jeopardizes China's sustainable development. Habitat International, 44, 130-136.

Zhou, G., Tan, Z., Cen, M., \& Li, C. (2006). Customizing visualization in three-dimensional urban GIS via web-based interaction. Journal of Urban Planning and Development, 132(2), 97-103.

Zhu, Q., 2015. Land acquisition compensation in post-reform china: evolution, structure and challenges in hangzhou. Land Use Policy, 46, 250-257.

Zi, C., Jie, W., \& Hong-Bo, C. (2016). $\mathrm{CO}_{2}$ emissions and urbanization correlation in China based on threshold analysis. Ecological Indicators, 61, 193-201. 